\title{
Innovation of teacher induction: Review on regional standardized training of beginning teachers in Shanghai
}

\author{
Zhao Xuan (Corresponding author) \\ Department of literature and education, Shanghai Open University \\ No.288 Guoshun Road, Yangpu District Shanghai, China \\ Visiting Research Scholarship in Graduate School of Education, The University of Tokyo \\ 7-3-1 Hongo,Bunkyo-ku,Tokyo 113-0033, Japan \\ Tel:8613482640049Ｅ-mail: zhaoxuan@sou.edu.cn
}

Received: December 2, 2018

doi:10.5296/jet.v6i1.13981
Accepted: December 14, 2018 Published: January 1, 2019

URL:http://dx.doi.org/10.5296/jet.v6i1.13981

\begin{abstract}
Since 2012, Shanghai has promoted regional standardized training of beginning teachers (RSTBT) for 6 years. Regional Education Bureau (REB), Teachers Training Colleges (TTC), kindergartens, primary and secondary schools (K-12 schools) of all 18 Districts have taken part in this program. Y district lied in the northeast of Shanghai. Its regional education bureau and teacher's training college promoted inductive training for new teachers, and finally accumulated rich experience in teacher induction.
\end{abstract}

Keywords: regional standardized training of beginning teachers (RSTBT), inductive training, induction program, teacher induction, beginning teacher (BT), teachers' professional development (TPD), Y district, Shanghai

\section{Introduction}

\subsection{The bridge to teacher professional development}

Becoming a teacher is a continuous life-long process. Critical stages include preservice education and preparation, teacher induction, and continuous professional development throughout whole career (Feiman-Nemser, 2001). In order to ease the "entry shock" into the school system (e.g., Kelchtermans \& Ballet, 2002) and to optimize socialization into the profession, formal induction programs have been implemented (e.g., Ingersoll, 2007; Ingersoll \& Smith, 2004; Wong, 2004). Programs vary across countries, as well as within countries (e.g., Howe, 2006; Wong et al., 2005).

After teacher pre-service training, teacher professional development is the next major step towards improving teachers' practices (Wong, 2004). High quality intensive professional 
development programs are crucial to train, support, and retain quality teachers (Wong, 2004). Teachers' professional development (TPD) is a long-term and systematic process through whole career, as part of the lifelong learning process (Gu, 1999; Ye, 2002; Ren, 2004; Liu, 2014). At the initial stage, induction programs support beginning teachers to acquire pedagogy knowledge, enhance teaching skills, devote into classroom management, continuously improve professional quality, and gradually grow into qualified teachers. (Liu, 1996; Ye, 1998; Gu, 1999; Ren, 2004; Liu, 2004).

Beginning teachers encounter a steady stream of distinct challenges especially in their first-year of teaching, and struggle in isolation to survive. Researches generally agree to provide support and assessment for beginning teachers during induction period. (Ball \& Goodson, 1985; Houston, 1990; Qu, 1990; Debolt, 1992; Ren, 2005) High-quality induction programs can overcome this challenge by accelerating beginning teachers' professional growth and making them more effective at the very start of career. Teacher induction reduce the rate of new teacher attrition, affects the orientation of career choice, alleviate physical and mental load, reduced stress during the transition, accelerate the professional growth of beginning teachers, increase retention, provide a positive return on investment, and improve students' learning. (Davis,1979; Australia Department of Education and Science, 1987; Joerger \& Brcmer, 2001) Induction provides opportunity for beginning teachers to link the theory of instruction learned in their teacher preparation programs with the practice of classroom teaching, under the guidance of experienced mentors, transition smoothly into school field (National Association of State Boards of Education, 2012).

According to current Chinese teacher employment system, induction period is generally equal to probation period, as set for a period of one year. First-year teachers are required to pass formative assessment and final evaluation, get teaching license and national certificate, and finally become formal teachers. According to teachers' laws, regulations, policies, and implementation practices, fresh graduates recruited as new teachers should be arranged for one year induction. Previous graduates which do not have more than one year's teaching experience also need to participate in induction program (Qu, 1990; Liu, 1996; Ye, 1998; Gu, 1999; Ren, 2004).

\subsection{Teacher Induction: Chinese Practice and Experience}

Chinese informal induction issues constitute of important part in fist probationary year as provides beginning teachers with continuous support and guidance. The purpose is to help beginning teachers overcome difficulties faced in daily teaching practice, improve classroom efficiency, feel less frustration, and adapt to the teachers' occupation role as soon as possible. Induction training constitutes of continuous teacher education after graduation, and it is the bridge between pre-service training and in-service training. The induction period is a key link of the professional development of teachers. During this period, new teachers receive vocational education continually, whether can be realized smoothly role changes from teacher students to competent teachers, not only affects the occupation tendency and employment persistence, but also affect determines the growth of teachers in their entire occupation career (Qu, 1990; Liu, 1996; Ye, 1998; Gu, 1999; Ren, 2005; Chen, 2008). 
Induction period usually refers to the first year when a beginning teacher is enrolled first time to a school and starts teaching. According to recent Chinese enrollment of teachers, the first year is generally equal to the probationary year, after passing phased assessment and annual evaluation, trainee teachers become formal teachers. The induction period is the continuous of pre-intern and preservice preparation held by universities and colleges (Qu, 1990; Liu, 1996; Ye, 1998; Gu, 1999; Ren, 2004; Chen, 2008).

Since long ago Chinese regional educational administration and enrollment schools has organized one year probationary or trainee for beginning teachers. "Teachers Law of People's Republic of China" clearly stipulates that "new teachers obtain the qualifications to teach at first time, there should be inductive" (MEPRC, 1993). However, Chinese inductive system is mainly from the aspect of personnel wage level, passing the examination after one year of inductive training, new qualified teachers finally get formal salary.

Chinese government and communities pay more attention to teachers' continuous education and in service training after 1990s, as providing beginning teachers with induction is gradually put on the agenda of Ministry of Education of the People's Republic of China (MEPRC). In Sep 1999 "Regulations for continuous education of school" was implemented, which pointed out that: "Primary and secondary school teachers' continuous education includes informal training and formal training. Informal training contains induction for beginning teachers. During induction period beginning teachers should participate in training no less than 120 hours" (MEPRC, 1999). In 2011 Ministry of Education of the People's Republic of China (MEPRC) issued "advice on strengthening of teachers' training", which stipulated: "Education administer should provide pre-service training for all new teachers, help new teachers adapt to career as soon as possible. Training time should not be set less than 120 hours" (MEPRC, 2011). During higher education stage normal students and student teachers are required to attend short-term intensive training as compulsory course, commonly contains of micro teaching practice, education intern and vocational training. After graduation, most student teachers will get teaching positions in kindergartens, primary and secondary schools, and participate in formal teaching under the traditional mentoring and guidance from schools. Trainee stage set for beginning teachers is basically limited to small range, which is usually an informal arrangement by schools. Mainly elder teachers get involved in providing counselling and guidance for novice teacher (Ren, 2004).

"The national long-term education reform and development plan (2010-2020)" has set future education strategic objects as "improve and implement current teachers' qualification system, strictly set vocational access for teachers." According to new teacher admittance mechanism, teacher candidate should pass national or provincial teacher certification exams before get formal recruitments. In order to implement of this outline, the 8th meeting of Shanghai education reform leading group clearly stated: "the establishment of standardized training system for beginning teachers should be established as soon as possible" (MEPRC, 2010). In March 2012, Shanghai enacted "the guidance of standardized training for beginning teachers (Trial) in Shanghai's kindergartens, primary and secondary schools", as initial teachers should take one year internship under the guidance of regionals Education Bureau and teachers' training college. Regional standardized training of beginning teachers (RSTBT) is designed as one year induction, concluding of systematic and in-service training (SMEC, 2012). Later Shanghai Municipal Education Commission (SMEC) awarded a certificate issued by 
standardized training of beginning teachers (STBT). Finally in September 2012 Shanghai began to promote of STBT comprehensively. (SMEC, 2012; Yue, 2015).

RSTBT is mainly led by district education bureau, organized by regional teacher training colleges, undertaken by teacher professional development schools (also known as training schools) and servicing schools (which have enrolled BT) through collaborative work, which is the cohesion and continue of student teacher education after graduating from colleges and universities. STBT is a significant program designed from top to bottom, promoted from bottom to top, as contributes for establishing professional access mechanism for first-year teachers served in kindergarten, primary and secondary schools (K-12 school). RSTBT not only promotes overall development of first-year teachers, but also improves mentors' professional literacy. RSTBT is a system-wide, coherent, comprehensive training and support process that continues for 1 year as part of the lifelong professional development program to retain first-year teachers and increase their effectiveness.

\section{Innovation in school field: explore mechanism for RSTBT}

\subsection{Bottom-to-top: construct the frame of RSTBT}

Regional standardized training of beginning teachers (RSTBT) is different from previous pre-service training and student teacher education held by universities and colleges during higher education. Regional education bureau designs frame of RSTBT program, and through a sustainable program model focuses on comprehensive induction systems for new teachers that improves their effectiveness, retention and leadership, and finally increased student learning. Teacher training college arranges schedule of RSTBT and provide professional training together with teacher development schools. To guarantee training effectiveness, beginning teachers' performance and evaluation during RSTBT will be incorporated into assessment and evaluation system both in teacher professional development schools and servicing schools which have enrolled those beginning teachers.

\subsection{Induction Mode: "3+1" immersion training}

The basic elements and arrangement of induction programs vary from different districts. Y district divided regional beginning teachers' standardized training (RSTBT) into 4 stages as "3+1" model since Aug 2013. Take 2013-2014 school year for example, RSTBT was constituted of: (a) Orientation, held by teachers' training college of Y district, usually began from late August 2013, and last 1 week. (b) First semester training (marked as training period I), held by teachers' professional development school, began from Sep 2013 to Jan 2014, usually last 1 semester. (c) Second semester training (marked as training period II), held by servicing schools, which began from Feb 2014 to Jun 2014, usually last 1 semester. (d) Centralized training, held by teachers' training college, began from August 2013 to Jun 2014, usually last half day per week. (Table 1) RSTBT helps beginning teachers to adapt to their new settings and roles. The methods tend to include mentoring, beginning teacher workshops, seminars and lectures, professional networks, peer collaboration, content focused groupings, meetings with principal, administrative observation, team work, reduced workload, common planning times, and extra resources. (Bartlett \& Johnson, 2010; Wechsler, Caspary, Humphrey, \& Matsko, 2012; Ingersoll \& Smith, 2004; Wang et al., 2008). 
Table 1. "3+1" immersion training model

\begin{tabular}{|c|c|c|c|c|}
\hline \multicolumn{5}{|c|}{ "3+1" immersion training model } \\
\hline & Orientation & Training section I & Training section II & Centralized training \\
\hline Schedule & $\begin{array}{l}\text { Late August } 2013 \\
\text { last } 1 \text { week }\end{array}$ & $\begin{array}{l}\text { From Sep } 2013 \text { to Jan } 2014 \\
\text { last } 1 \text { semester }\end{array}$ & $\begin{array}{l}\text { From August } 2013 \text { to Jun } 2014 \text {, } \\
\text { last } 1 \text { year }\end{array}$ & half day per week \\
\hline $\begin{array}{l}\text { Undertaker } \\
\text { \&Organizer }\end{array}$ & TTC of Y district & TPD schools & servicing schools & TTC of Y district \\
\hline
\end{tabular}

2.3 Induction Path: Pilot teachers' lead, veteran teachers' instruct, team work, peer cooperation

Since August 2012, Y district carried out mixed induction mode, constituted of pilot teachers' lead, veteran teachers' instruct, team work, peer cooperation and learning community.

Effective mentors are at the heart of every high-quality induction program. (NTC,2011)The selection, training, ongoing support and thoughtful utilization of teacher mentors is critical to the provision of impactful, instructionally focused support to beginning teachers.(NTC,2012; Clandinin et al., 2012; Long et al., 2012; Ingersoll \& Strong, 2011; Totterdell et al., 2008; Whisnant et al., 2005) Regional education bureau and teachers' training college s determine mentor qualifications focused on teaching experience, teaching excellence, as well as communication and interpersonal skills. Honored educationists, pilot teachers, and veteran teachers are appointed by administrators as mentors for RSTBT. At the same time, teacher professional development schools and servicing schools also appoint excellent teachers as part-time supervisors. Throughout the school year, mentors work with beginning teachers during and after school to promote growth. Mentors are provided with an orientation to the induction program and instructional mentor training. Besides formal mentor training, mentors also participate in facilitated professional learning communities of instructional practice to refine mentoring skills and increase induction practices. Mentors also benefit from induction.

\subsection{Balance workload: multi-channel implementation of teachers'flexible flow}

The mainly contradiction between professional training and full time job focused on time constraint which is always the urgent problem faced by beginning teachers. In order to solve this problem, Y District put forward nursery teacher exchange method between kindergartens. 
As training kindergartens accept one beginning teacher to receive immersion training in campus, while send out one mature teacher to support serving kindergarten. This mature teacher replaces the position and job of beginning teacher in serving kindergarten till finish of training section I. Primary school and secondary schools enroll supplementary teacher to replace beginning teachers' position in serving school during training section I. While leaving form serving school and inducted in training school, beginning teachers are required to reduce teaching load carry no more than 80 percent classroom instruction assignment to allow for mentoring activities to occur. The implementation of teachers' flexible flow system, release time pressure, and ensure beginning teachers' participation in RSTBT.

Since the promotion of implementation of teachers' performance salary in Shanghai, job position control in every school is stricter. Mature teachers afford full load of task. Servicing schools send out beginning teachers to participate in full-time training. This has caused great difficulties and pressure on servicing school arrangements. Training schools assign mentors for beginning teachers after accept them from servicing schools. Administrators should reduce workload for mentors to allow time for observations, planning, learning, and reflection. Since flexibility in mentor caseloads depending on the teaching workload of the mentor, induction program should provide mentors with regular release time, and assign full-time mentors who are able to support larger caseloads of beginning teachers. Flexible implementation of teacher flow system support both training schools and servicing schools through teachers' exchange inside regional education unit and alliance.

\section{Framework for RSTBT design}

\subsection{Vision statement}

RSTBT share a common goal of providing new teachers with assistance, guidance, and support to ease their gradual acculturation into the teaching profession (Howe, 2006; Stoel \& Thant, 2002). RSTBT requires all beginning teachers to participate at the very start of their first-year of teaching. RSTBT program lasts one year and provide beginning teachers with universal, high-quality induction and mentoring support, thereby enhancing the quality of teaching and increasing student learning. RSTBT establishes a comprehensive and cohesive framework for preparing, mentoring, and providing professional development for both beginning teachers and mentors, and promotes professional norms of inquiry and continuous learning.

Beginning teachers are orientated to the district, school and community. Emotional supports are provided by the community as beginning teachers are contributors to the school's learning community.

\subsection{Qualifications, Selection, and Training of Mentors}

Mentors are expected to be veteran teachers who have experience teaching the same grade levels and subjects taught by the inductee teachers. Their task is to help inductee teachers become familiar with school norms and procedures, assist them in adapting to the school culture, aid them in instructional planning and classroom management, and provide constructive feedback on their teaching through formative evaluation.

RSTBT assigns qualified mentors and provides guidance and clear expectations for the mentoring. Qualifications for mentors must include but are not limited to: 1) Minimum of 10 years of effective teaching experience; 2) Ability, willingness, and flexibility to meet needs 
for supporting inductee teachers, participation in professional preparation to acquire the knowledge and skills needed to be an effective mentor; 3) Demonstrated commitment to professional learning and collaboration, and share instructional ideas and materials with beginning teachers; 4) experience and certification in the subject teaching; 5) knowledge about adult learning theory, social and workplace norms, resources and opportunities in the district; 6) ability to be reflective and articulate about the craft of teaching; 7)Assigned to new teachers by three categories (in order of priority): same building, same grade and same subject area.

RSTBT provide ongoing training and support for mentors that include, but are not limited to: 1) Goal setting - know essential characteristics of mentoring adults, regard the duties and responsibilities of a mentor; 2) Coaching and mentoring - get opportunities to participate in foundational training and ongoing professional learning community of mentoring practice; 3 ) Use of appropriate mentoring instruments, protocols and formative assessment; 4) Engage in self-assessment to reflection their own development as teachers and mentors; 5) Address the specific and varied performance needs of mentees, coordinate of appropriate resources to address the performance needs of mentees, and support beginning teacher's growth and effectiveness.

\subsection{Structure of inductive module and curriculum}

Main characteristics of RSTBT program infrastructure is establishing inductive curriculums package, and divided into 3 levels: regional training, school training, and individual instructing.

Table 2. Regional Training Module and Curriculum

\begin{tabular}{|l|l|}
\hline \multicolumn{2}{|c|}{ Regional Training Module and Curriculum } \\
\hline Formal Orientation & $\begin{array}{l}\text { Introduction of general district procedures, policies, and responsibilities } \\
\text { Introduction of RSTBT }\end{array}$ \\
\hline Morality and Literacy & Professional Literacy \\
\hline Knowledge and Skill & $\begin{array}{l}\text { Students' learning theories } \\
\text { Educational technology } \\
\text { Calligraphy training } \\
\text { Overview of curriculum standards and guidelines } \\
\text { PCK }\end{array}$ \\
\hline Practice and Experience & $\begin{array}{l}\text { Campus safety emergency response } \\
\text { Teaching methodology } \\
\text { Instructional design } \\
\text { Classroom management }\end{array}$ \\
\hline Online Course & Micro Lesson for specific subject \\
\hline Resources & $\begin{array}{l}100 \text { Q\&A for Beginning Teacher } \\
\text { Create vibrant learning communities and peer mentoring networks. }\end{array}$ \\
\hline
\end{tabular}




\section{Macrothink Institute}

Regional training consists of a series of professional development goals, as: (1) links induction with local and national standards for teaching; (2) introduces beginning teachers to general district procedures, policies, and responsibilities;(3) clarify expectations for the role of beginning teacher;(4) describe key skills, knowledge and attributes and the professional learning and development needed by beginning teachers to fulfil this role adequately (Table 2).

School training start after assignment of a mentor to beginning teacher, focused on: professional networks, peer collaboration, content focused groupings, meetings with principal, administrative observation, reduced workload, common planning times, and extra resources (Table 3).

Table 3. School Training Module and Curriculum

\begin{tabular}{|l|l|l|}
\hline \multicolumn{2}{|c|}{ School Training Module and Curriculum } \\
\hline \multirow{3}{*}{ Kindergarten } & Informal Orientation & $\begin{array}{l}\text { Includes a review of basic school procedures and policies } \\
\text { such as how to order supplies, how to organize a } \\
\text { classroom, and where to find instructional resources. }\end{array}$ \\
\cline { 2 - 3 } & In-service training & $\begin{array}{l}\text { Nursey and first aid } \\
\text { Kid Psychology } \\
\text { Design and organize actives and games }\end{array}$ \\
\hline Primary and & Informal Orientation & $\begin{array}{l}\text { Informal Orientation: Includes a review of basic school } \\
\text { procedures and policies such as how to order supplies, } \\
\text { how to organize a classroom, and where to find } \\
\text { instructional resources. }\end{array}$ \\
\cline { 2 - 3 } Secondary school & In-service training & $\begin{array}{l}\text { Group research of teaching } \\
\text { Classroom observation and analysis } \\
\text { Classroom management } \\
\text { Head teacher's responsibility }\end{array}$ \\
\hline
\end{tabular}

During individual instructing, mentors may offer beginning teachers with occasional advice actively get involved in instructional practice; link induction with local and regional standards for teaching; and bridge the gap between theory and practice for new teachers. Individual instructing may last after induction. So beginning teachers can hold opportunities for in-depth learning and cooperation (Table 4).

Table 4. Individual Instructing Module

\begin{tabular}{|l|l|}
\hline \multicolumn{2}{|c|}{ Individual Instructing Module } \\
\hline \multirow{3}{*}{ Introduction } & Assigned to a mentor or supervisor \\
\cline { 2 - 3 } & Join in teaching group of specific subject \\
\hline \multirow{4}{*}{ Mentor \& Coach } & Peer coaching \\
\cline { 2 - 2 } & Participate in group research \\
\cline { 2 - 2 } & Classroom observation and analysis \\
\hline
\end{tabular}




\subsection{Evaluation System of RSTBT}

Program evaluation is critical for continuous improvement. It involves the regular collection of data of implementation and impact to improve the program. It describes the process for gathering, reviewing, and analyzing evaluation data and providing timely program adjustments (Oakley, 1998; Hunter, 2016). RSTBT leadership tries to design a reliable infrastructure to support the collection, analysis, and use of standards-based data to promote continuous high quality program improvement and sustainability. RSTBT evaluation system is used to help all program participants reflect on their practice, collaboratively analyze observation data, develop next steps, and drive ongoing program improvement (Table 5).

Table 5. RSTBT Evaluation System

\begin{tabular}{|c|c|c|c|c|c|c|c|}
\hline \multicolumn{8}{|c|}{ RSTBT Evaluation System } \\
\hline & $\begin{array}{l}\text { Self } \\
\text { Assessment/ } \\
\text { Summary }\end{array}$ & $\begin{array}{l}\text { Peer } \\
\text { Review }\end{array}$ & $\begin{array}{l}\text { Formative } \\
\text { Assessment }\end{array}$ & $\begin{array}{l}\text { Performance } \\
\text { Assessment }\end{array}$ & $\begin{array}{l}\text { Regular \& Ongoing } \\
\text { Evaluation }\end{array}$ & $\begin{array}{l}\text { Termly } \\
\text { Assessment }\end{array}$ & $\begin{array}{l}\text { Annual } \\
\text { Evaluation }\end{array}$ \\
\hline Beginning teacher & $\sqrt{ }$ & $\sqrt{ }$ & $\sqrt{ }$ & $\sqrt{ }$ & $\sqrt{ }$ & $\sqrt{ }$ & $\sqrt{ }$ \\
\hline Mentor & $\sqrt{ }$ & $\sqrt{ }$ & & $\sqrt{ }$ & & $\sqrt{ }$ & $\sqrt{ }$ \\
\hline $\begin{array}{l}\text { Training school/ } \\
\text { TPD school }\end{array}$ & $\sqrt{ }$ & $\sqrt{ }$ & & $\sqrt{ }$ & $\sqrt{ }$ & $\sqrt{ }$ & $\sqrt{ }$ \\
\hline Servicing school & $\sqrt{ }$ & $\sqrt{ }$ & & $\sqrt{ }$ & $\sqrt{ }$ & $\sqrt{ }$ & $\sqrt{ }$ \\
\hline $\begin{array}{l}\text { Regional teachers' } \\
\text { training college }\end{array}$ & $\sqrt{ }$ & & & $\sqrt{ }$ & $\sqrt{ }$ & $\sqrt{ }$ & $\sqrt{ }$ \\
\hline Induction program & $\sqrt{ }$ & & & $\sqrt{ }$ & $\sqrt{ }$ & $\sqrt{ }$ & $\sqrt{ }$ \\
\hline
\end{tabular}

Evaluation of induction program has focused mainly on RSTBT's positive impact on teacher retention, as well as on their contribution to the development of effective instructional skills among beginning teachers (Rippon \& Martin, 2003; Villar \& Strong, 2007).

Sub evaluation for beginning teacher reported that how induction programs positively affected their teacher commitment, classroom instructional practices, and student achievement. Beginning teachers are required to fill in inductee needs questionnaire at the beginning of semester, rate the following topics relative to the amount of support beginning teacher's need: lesson planning and progress monitoring, organize and classroom management, instructional skills and teaching strategies, resource and support, as well as building initiatives (Commonwealth of Pennsylvania Department of Education, 2008).

Assessment of mentor's work involves of weekly contact time between mentors and new teachers, mentor release time, mentor professional development, knowledge and skill base, educational leadership, reflective practice, communication and feedback. According to the evaluation, specific training elements will be provided in next semester, including such components as: knowledge of state teaching standards, formative assessment of beginning teachers' performance, promote classroom observation, conduct reflective conversations, and adult learning theory. As more than 95\% RSTBT's mentors are part-time, so it is necessary to set a minimum amount of mentor release time, and require of foundational mentor training and on-going mentor learning. 
Both TPD school and servicing school should finish self-summary before the end of a semester, at the same time participate in termly assessment and annual evaluation, and accept experts' inspect and access organized by District Education Bureau and regional teacher' training college. School investigation focused on school rules \& regulation, induction program plan \& progress, teacher involvement \& principal engagement, efficacy \& innovation, commitment \& support.

\section{Conclusion}

The quality of a teacher's experience in the initial years of teaching is critical to forming positive attitudes to teaching as a career (Bezzina, 2006). The early years of a teaching career have long been recognized as a critical stage that can either provide a strong foundation for high performance as a teacher or lead to disillusionment and high levels of attrition. Kane and Russell (2003) described the first years of teaching as the "survival stage" of teacher development, with beginning teachers' continuing to develop their skills and knowledge well into teaching. The challenge is how to induct beginning teachers into professional career which require a high level of professional practice and competencies.(Doris Choy et al, 2013)There is growing evidence that teacher induction and mentoring programs can help beginning teachers to acquire the knowledge and skills from more experienced teachers, adapt to school culture more quickly, and be more satisfied with their work (Darling-Hammond, 1995; Gold, 1996; Huling-Austin, 1992).

The importance of teacher induction is wildly accepted in Shanghai since the beginning of 21 century. Before the implement of RSTBT, Shanghai provides comprehensive and multifaceted induction programs for new teachers, which are similar to the approach used in teacher's professional development. All teachers in Shanghai are assigned to a mentor, while new teachers have two mentors. One mentor focused on subject-specific teaching skills, and the other focused on classroom management. Observation occurs in both directions - the new teacher observing and learning from the mentor, and the mentor observing and providing feedback to the new teacher ( Asia Society, 2014).

RSTBT has piloted and spread in Shanghai since Sep 2012. As a formal teacher induction program, RSTBT is the continue of initial teacher education and pre-service training. Simultaneously RSTBT should be the bridge between teacher preparation program and the beginning of one's teaching career. RSTBT engaged regional education bureau, regional teacher's training college, training school/teacher development school, and servicing school together as shareholders on supporting beginning teachers. RSTBT tries to create ideal process of induction by operating on 2 levels: the profession and the work setting. Beginning teachers are inducted into a community of practice where all the teachers, working together, clarify the meaning of learning to teach and their implications for improved teaching in daily interactions with students and colleagues. Inducting novices into professional standards and incorporating them into a community of practice take a backseat to the goal of easing their entry into teaching. Participation in RSTBT and contribute to an increase in skill knowledge, build higher levels of confidence, and intrinsic motivation, finally lead to an increase in teacher retention and sense of self-efficacy. 


\section{References}

Alliance for Excellent Education (AEE). (2006). Tapping the Potential:Retaining and Developing High-Quality New Teachcrs. Washington,D.C:Alliance for Excellent Education, 11.

Asia Society Global Cities Education Network. (2014). Early Teacher Development: Trends and Reform Directions. A Global Cities Education Network Report. Retrieved from https://asiasociety.org/files/gcen-earlyteacherdevelopment.pdf.

Breaux, A. L., \& Wong, H. I. C. (2003). New Teacher Induction:How to Train, Support and Retain New Teachers. CA: Harry K. Wong Publications, Inc., 87.

Castetter, W. B. (1981). The Personnel Function in Educational Adniinistration. New York: McMillan, 190.

Chen, L. (2008). A comparative study of British and American beginning teacher evaluation. Master's thesis of East China Normal University.

Chen, W. (2008). Professionalization of Western University Teachers. Peking University press, 17.

Choy, D., Wong, A. F., Lim, K. M., \& Chong, S. N. Y. (2013). Beginning teachers' perceptions of their pedagogical knowledge and skills in teaching: A three year study. Australian Journal of Teacher Education, 38(5), 68-79.

Davis, D. J. (1979). The Liverpool Induction Pilot Scheme: Summative Report. School of Education, University of Liverpool.

Department of Education and Science (DES). (1987). Quality in Schools: The Initial training of Teachers: An HMI Survey. London: HMSO.p23

Gary, P. D. (n.d.). Teacher Induction and Mcntoring:School-Based Collaborative Programs. New York: State University of New York Press, 15.

Guo, H. (2010). The British teacher professional standards: humanistic vision research. Master's thesis of East China Normal University, 21-24.

Hunter. W. (2016). New Teacher Induction: A Program Evaluation. Dissertations, Theses, and Masters Projects. Paper 1463428445.

Joerger, R. M., \& Brcmer, C. D. (2001). Teacher Induction Programs: A Strategy for Improving the Professional Experience of Beginning Career and Technical Education Teachers. OH:National Dissemination Center for Career and Technical Education,2.

Kang, J. (2006). The new teacher training reform of America. Master's thesis of Hebei Normal University, 19-25.

Kong, Y.J. (2010). A study on the relationship between novice teachers'vocational education and teaching adaptation in Higher Vocational Colleges. Master's thesis of Yanbian University, 11-15.

Li, H. (2008). A study on novice teachers' Vocational Education. Master's thesis of Shanghai Normal University, 13.

London, H. (2003). Creating A New Teacher Induction Program that Works. NEA Today, March, 41. 
Mager, G. M. (1992). The Place of Induction in Becoming a Teacher.

Ministry of Education of the People's Republic of China (MOE). (2017). Law of Teachers of the People's Republic of China. Retrieved from http://www.moe.edu.cn/s78/A02/zfs__left/s5911/moe_619/tnull_1314.html,2017-02-02.

Ministry of Education of the People's Republic of China (MOE). (2017). Provisions on continuing education in primary and secondary schools. Retrieved from http://www.gov.cn/fwxx/bw/jyb/content_2267058.htm.

Ministry of Education of the People's Republic of China (MOE). (2017). Opinions of the Ministry of education on strengthening the training of teachers in primary and secondary schools. Retrieved from http://www.moe.edu.cn/publicfiles/business/htmlfiles/moe/s4559/201101/114220.html.

Ministry of Education of the People's Republic of China (MOE). (2017). National medium and long term education reform and development plan (2010-2020). Retrieved from http://www.moe.edu.cn/publicfiles/business/htmlfiles/moe/moe_838/201008/93704.html.

Mu, L. (2003). On the establishment of lifelong education system in China. Journal of Henan Institute of Science and Technology, 40-42.

Oakley, K. (1998). The Performance Assessment System: A Portfolio Assessment Model for Evaluating Beginning Teachers. Journal of Personnel Evaluation in Education, 11, 323-341.

Qu, Z. (2017). On the significance of the new concept of education to promote the professional development of Teachers. Retrieved from http://www.jxteacher.com/ruzi/column59888/22e091cc-c486-4933-8fe0-bff703d298cf.ht $\mathrm{ml}, 2014-3-28$

Ren, X.Y. (2005). A comparative study on the theory and practice of teachers' Vocational Education. Northeast Normal University press.

Ren, X.Y., \& Li, G. (2004). A study on Teachers' vocational education and its goals. Foreign primary and secondary education, 11.

Shanghai Municipal Education Commission. (2017). Guidance on standardized training of primary and secondary school (Kindergarten) teachers in Shanghai (Trial). Retrieved from http://www.shmec.gov.cn/html/xxgk/201204/406112012007.php.

Wang, L. G. (2007). A study on Teachers' quality standards based on Teachers' professional development. Doctoral Dissertation of Northwest Normal University, 23-24.

Wang, Y.L. (2012).Review on the development of English teachers' specialization in primary schools. Lyceum:Education and research, 13, 22-23.

Wei, D. (2010). Narrative research on the formation of new teachers' professional ethics. Master's thesis of Anhui Normal University,23.

Xie, M. F. (2010). Determination of college graduates'working hours. Human resource management, 96-97.

$\mathrm{Xu}, \mathrm{M}$., Huang, X. N. (2002). On the professional development of new teachers in America from the perspective of vocational training. Educational Science, 51-55. 


\section{Macrothink}

Yin, F. (2015). The construction of teachers' development support system based on 2019, Vol.6, No.1 professional maturity: a case study of Pudong New Area's teachers' hierarchical training in Shanghai. Education and teaching research, 29, 35-37.

Yue, Y., \& Wu, G.F. (2015). The characteristics and enlightenment of the standardized training for the beginning teachers in Shanghai. Basic education research, 5, 19-21.

Zhang, P. (2010). Attach importance to reflection in the growth of new teachers. Chinese Education Innovation Herald, 12, 181.

\section{Copyright Disclaimer}

Copyright reserved by the author(s).

This article is an open-access article distributed under the terms and conditions of the Creative Commons Attribution license (http://creativecommons.org/licenses/by/3.0/). 